\title{
Multiple Processes in Prospective Memory Retrieval: Factors Determining Monitoring Versus Spontaneous Retrieval
}

\author{
Gilles O. Einstein \\ Furman University
Ruthann Thomas, Sara Mayfield, and Hilary Shank
Furman University

\author{
Mark A. McDaniel \\ Washington University in St. Louis \\ Nova Morrisette \\ University of New Mexico
}

\author{
Jennifer Breneiser \\ Washington University in St. Louis
}

\begin{abstract}
Theoretically, prospective memory retrieval can be accomplished either by controlled monitoring of the environment for a target event or by a more reflexive process that spontaneously responds to the presence of a target event. These views were evaluated in Experiments 1-4 by examining whether performing a prospective memory task produced costs on the speed of performing the ongoing task. In Experiment 5, the authors directly tested for the existence of spontaneous retrieval. The results supported the multiprocess theory (M. A. McDaniel \& G. O. Einstein, 2000) predictions that (a) spontaneous retrieval can occur and can support good prospective memory and (b) depending on task demands and individual differences, people rely to different degrees on monitoring versus spontaneous retrieval for prospective remembering.
\end{abstract}

Keywords: prospective memory, monitoring theory, spontaneous retrieval theory, multiprocess theory

Episodic memory has typically been conceptualized and studied as a system or process that functions to preserve an individual's mental record of his or her personal past. Tulving (2004) recently suggested that the episodic memory system may play an even more fundamental role in human existence and the success of the species. The idea is that the autonoetic awareness (self-knowing consciousness) that characterizes and is supported by explicit episodic memory also allows people to mentally place themselves forward in time (proscopic chronesthesia in Tulving's, 2004, terms). This kind of orientation arguably supports the planning and forward-looking activities that are a hallmark of human existence

Gilles O. Einstein, Ruthann Thomas, Sara Mayfield, and Hilary Shank, Department of Psychology, Furman University; Mark A. McDaniel and Jennifer Breneiser, Department of Psychology, Washington University in St. Louis; Nova Morrisette, Department of Psychology, University of New Mexico.

This project was supported by the National Aeronautics and Space Administration Grant NCC-2-1085. We thank Meredith Edwards, Mary Neill Hagood, Alicia Niles, and Laura Summers for their help in testing participants and analyzing data. Portions of Experiments 1 and 3 were presented at the 2002 meeting of the Psychonomic Society, Kansas City, KS; portions of Experiments 4 and 5 were presented at the 2003 meeting of the Psychonomic Society, Vancouver, Canada; and portions of Experiments 3 and 4 were presented at the 2004 meeting of the American Psychological Society, Chicago, IL.

Correspondence concerning this article should be addressed to Gilles O. Einstein, Department of Psychology, Furman University, Greenville, SC 29613. E-mail: gil.einstein@ furman.edu (e.g., Johnson \& Sherman, 1990). We believe that a central and ubiquitous function of productive proscopic chronesthesia is prospective memory (hereafter abbreviated as PM). PM is memory for actions to be performed in the future such as remembering to give a message to a friend or remembering to take medication. It has often been contrasted with retrospective memory (abbreviated as $\mathrm{RM}$ ), which is memory for past events such as memory for a list of words learned in an experiment, memory for the plot of a recently seen movie, and memory for the names of former teachers. It is interesting to note that prior to the past 20 years or so, nearly all memory research focused on examining RM.

Although there are potentially many interesting dimensions along which PM and RM tasks differ (Ellis, 1996; Kvavilashvili \& Ellis, 1996), following Craik (1986), our focus in this article is on the difference at retrieval. A characteristic of explicit tests of RM is that the experimenter at some point puts the participant in a retrieval mode (Tulving, 1983) and directs the participant to retrieve previously experienced episodes. By contrast, PM requires that at some point in the future, individuals remember to perform an action without being put in a retrieval mode by an external agent. A typical paradigm for studying PM, for example, involves asking participants to remember to press a key whenever they see a particular target item in the context of an ongoing task (such as rating words for pleasantness). In this paradigm, participants are not explicitly asked (e.g., by an experimenter) to search memory when the target event occurs. Thus, when a PM target event is encountered, the participant must somehow switch from seeing the item as an item to be rated to thinking about the item as a cue for an intended action. 
One approach to understanding how people accomplish this kind of retrieval is to assume that human beings have an executive attentional system that consciously monitors the environment for PM target events. Another approach is to assume that the cognitive system relatively automatically responds to the occurrence of target events in the environment (McDaniel, Guynn, Einstein, \& Breneiser, 2004).

According to Bargh and Chartrand (1999; see also Posner \& Snyder, 1975), "This question of how much conscious control we have over our judgments, decisions, and behavior is one of the most basic and important questions of human existence" (p. 463). They make a strong case that actions are often direct products of unconscious processes initiated by stimuli in the environment. Social psychologists, for example, have shown that stereotypes of a group are reflexively activated upon perception of group membership (Banaji \& Hardin, 1996; Bargh, 1994). Bargh and Chartrand have argued that it is adaptive to rely on automatic processes, as conscious direction over behavior is a limited resource that is quickly exhausted. For the most part, Bargh and Chartrand have focused on well-learned behavioral tendencies and long-standing goals, and how these are automatically activated by features of the environment. At issue is whether this reasoning can be extended to unique, episodically bound intentions.

The main goal of the present research is to evaluate monitoring and more automatic (spontaneous retrieval) approaches to explaining event-based PM retrieval. Event-based tasks are those in which the occurrence of an external event signals that it is appropriate to perform an action (Einstein \& McDaniel, 1990).

\section{Monitoring}

One type of theory, which we label monitoring theory, assumes that PM retrieval occurs through the capacity-demanding attentional process of monitoring the environment for the target events. The idea is that upon developing a PM intention, an executive attentional system, such as Shallice and Burgess' (1991) supervisory attentional system, monitors the environment for the target event. Once a target event is encountered, the executive attentional system interrupts the ongoing activity, and if the conditions are appropriate, initiates the processes necessary for performing the intended action. Recently, Smith (2003) presented a strong version of this view. She stated that

retrieval of an intention will never be automatic, because nonautomatic preparatory processes must be engaged during the performance interval, or the time in which the opportunity to carry out the action is likely to occur, but before the occurrence of the target event. (p. 349)

Smith and Bayen's (2004) formal multinomial model reinforces this theoretical position: The only path to PM retrieval in their model is through monitoring. Research showing that dividing attention during retrieval decreases PM performance (Einstein, Smith, McDaniel, \& Shaw, 1997; Marsh \& Hicks, 1998; McDaniel, Robinson-Riegler, \& Einstein, 1998; Park, Hertzog, Kidder, Morrell, \& Mayhorn, 1997) supports the monitoring theory. One interpretation of these results is that dividing attention interferes with an executive monitoring process that is necessary for identifying events in the environment as PM targets.
Smith (2003) presented evidence that performing an eventbased PM task concurrently with an ongoing task slows processing on an ongoing task. The PM task in her research was to press a key whenever any one of six target items occurred, and the ongoing task was to make lexical decisions as quickly as possible. Some participants performed only the lexical decision task, whereas others were asked to perform both. Lexical decision latencies were slowed substantially (e.g., from 736 ms to $1061 \mathrm{~ms}$ in Experiment 1) when concurrently performing the PM task. Because this slowing occurred on non-PM target trials, Smith's interpretation was that participants were expending significant resources monitoring the letter strings for the PM targets. Moreover, those whose PM performance was above the mean were slower on the lexical decision task than those below the mean.

\section{Spontaneous Retrieval}

A different type of theory, which we label spontaneous retrieval theory, proposes that people rely on spontaneous memory-based and/or attentional processes to retrieve intentions when PM targets are encountered (Einstein \& McDaniel, 1996; Guynn, McDaniel, \& Einstein, 2001; McDaniel \& Einstein, 2000; McDaniel et al., 2004). The assumption is that participants do not monitor the environment for target events and instead that remembering occurs when the presence of the target event initiates successful retrieval processes. We use the term spontaneous to reflect the assumption that retrieval can occur without executive resources devoted to the PM intention at the time that the target event first occurs. We are not implying that participants do not occasionally think about the PM task between the initial encoding of the intention and the later retrieval when the target event occurs (see Kvavilashvili, 1987), rather we are suggesting that no resources need to be devoted to evaluating the target event as a PM cue at the moment that it is first processed.

A specific example of a spontaneous retrieval theory is the reflexive-associative theory (Einstein \& McDaniel, 1996; Guynn et al., 2001; McDaniel \& Einstein, 2000; McDaniel et al., 1998, 2004). According to the reflexive associative theory, participants during planning form an association between the target cue and the intended action. Later, when the target event is encountered, an automatic associative system (like the hippocampal system proposed by Moscovitch, 1994) delivers the intended action to consciousness. According to Moscovitch, this retrieval is a relatively automatic process that occurs rapidly, obligatorily, and with few cognitive resources. Whether the retrieval occurs, however, depends on the extent to which the cue is fully processed at retrieval and the degree to which participants form a good encoding between the cue and the intended action. ${ }^{1}$

Before describing support for the spontaneous retrieval view, we note that the previously described findings of negative effects of dividing attention on PM performance do not necessarily argue against the reflexive-associative view. It may be, for example, that dividing attention interferes with full processing of the target event which is thought to be important for associative retrieval (Moscovitch, 1994). Also, the locus of the divided attention effect may not

\footnotetext{
${ }^{1}$ For the interested reader, another example of a spontaneous view of PM retrieval is the discrepancy detection theory (McDaniel et al., 2004).
} 
be on retrieving the intention but rather on increasing working memory demands to the extent that participants have difficulty selecting the retrieved intention and scheduling the intended action while it is still activated in working memory (Einstein, et al., 1997).

The idea that participants depend on spontaneous retrieval is consistent with introspective reports in our previous studies (Einstein \& McDaniel, 1990) in which many participants indicated that the thought of the PM action seemed to "pop" into mind while they were performing the ongoing task. Consistent with these postexperimental self-reports, Reese and Cherry (2002) probed participants at various points during an experiment, and participants rarely mentioned the PM task. Despite relatively high-PM performance (about 60\%), younger and older adults mentioned thinking about the PM task less than 5\% of the time (this compares with reported thoughts about the ongoing task about $69 \%$ of the time). If participants were relying on a strategic monitoring process, one would expect much more frequent reports of thoughts of the PM task.

Also consistent with the spontaneous retrieval theory is a contextual effect finding by Nowinski and Dismukes (in press). They presented participants with several different ongoing tasks to perform, but importantly they gave participants the PM instruction (to press a key when a target occurred) only in the context of one of these tasks. They found that the occurrence of the target led to better prospective remembering when it occurred in the context that matched the original encoding context. Their interpretation was that reinstating the context at retrieval facilitated retrieval of the cue-target association (see also McDaniel et al., 1998). It is unclear how to interpret this result from a straightforward monitoring perspective where the main demand is to maintain vigilance.

\section{The Multiprocess Framework}

McDaniel and Einstein (2000) proposed the multiprocess view, which takes into account evidence for both monitoring and spontaneous retrieval processes. This theory assumes that whether one relies on a monitoring or spontaneous retrieval process depends on the characteristics of the PM task, the ongoing task, and also the individual. Given the prevalence of prospective demands in everyday life, McDaniel and Einstein argued that it is adaptive to have a flexible system that can accomplish PM retrieval though several mechanisms. According to the multiprocess view, there is a general bias to rely on spontaneous retrieval. It would be maladaptive to depend exclusively on a monitoring process that heavily taxes working memory resources because (a) people often have multiple, simultaneous PM demands and (b) the delays before they can perform intended actions are often substantial. Further, the particular method that people use to help them remember to perform actions in the future depends on a variety of factors including the importance of the PM task, the characteristics of the target event and their relation to the target actions, the nature of the ongoing task, and individual differences (see McDaniel \& Einstein, 2000, for explanations of how these variables are expected to affect PM strategies that people use).

The primary approach of the present research followed that of Smith (2003; see also Guynn, 2003, and Marsh, Hicks, \& Watson, 2002), and evaluated the costs of performing a PM task on the speed and accuracy of performing the nontarget ongoing task items. If performing a PM task produces substantial increases in the time (or decreases in the accuracy) to perform the ongoing task (for nontarget items), then this would be evidence that participants were relying on monitoring. Moreover, to the extent that a monitoring process is needed for PM performance, monitoring levels should be indicative of PM performance. In contrast, finding minimal or no effects of performing a PM task on the efficiency of processing the nontarget items would suggest that participants were relying on a spontaneous retrieval process. Further, according to this view, high levels of PM performance can occur under conditions of no monitoring.

The multiprocess theory suggests that both patterns can emerge. To directly test this approach, we drew from the multiprocess view to vary the PM task in principled ways that are expected to modulate the extent to which participants relied on a monitoring strategy for PM retrieval. According to the multiprocess view, costs are more likely when the importance of the PM task is emphasized (Experiment 1), when focal processing of the target is not encouraged by the ongoing task (Experiments 1 and 2), and when there are multiple target events (Experiment 3 ). There should be no or minimal costs, however, when moderate emphasis instructions, a single target, and an ongoing task that encourages focal processing of the target are used (Experiments 1-4).

An important assumption of the monitoring view is that retrieval of an intention cannot occur without monitoring of the environment for the target event (Smith, 2003). In Experiment 5, we discouraged monitoring by telling participants to ignore the PM task during an intervening lexical decision task. Slowing down of lexical decision times to PM target events would indicate spontaneous retrieval.

\section{Experiment 1}

The multiprocess view suggests that PM retrieval processes will generally vary across focal and nonfocal target events (McDaniel \& Einstein, 2000). The target event becomes a focal cue when there is high overlap between the information relevant to performing the ongoing task and the specific target event (i.e., the ongoing activity encourages focal processing of the target; see Maylor, 1996, and Maylor, Darby, Logie, Della Sala, \& Smith, 2002, for a similar view). An everyday example of a focal cue would be encountering and pausing to converse with the friend to whom you intended to give a message. Following from the automatic activation view in which a key requisite for spontaneous retrieval is full processing of the target event (cf. Moscovitch, 1994), PM retrieval is likely to occur spontaneously in this situation. On the other hand, the target event is nonfocal when the target is not part of the information extracted by the person in the service of her or his ongoing activity. An example of a nonfocal cue would be a grocery store (for stopping to buy bread) located a bit off the road when one is traveling in rush hour traffic (and attending to other cars). With this type of target event, spontaneous retrieval is unlikely (see Rendell, McDaniel, Forbes, \& Einstein, 2005, for indirect support for these claims in research on age-related differences in PM).

To examine directly whether different processes are recruited for different PM tasks and whether PM retrieval can occur spontaneously, we varied focal processing of the target event. The ongoing task involved presenting a word and a category heading 
and asking participants to decide as quickly as possible whether the word was a member of the category. Participants in the focal condition were asked to press a key whenever a target word (e.g., tortoise) occurred, whereas participants in the nonfocal condition were asked to press a key whenever a target syllable (e.g., tor) occurred. We assumed that the target syllable is not focal because the ongoing category judgment requires processing of the stimulus as a unitized lexical item, which is a process that does not routinely emphasize conscious awareness of syllable information. We also varied the importance of the PM task. We examined the effects of these manipulations on PM performance and also, importantly, on the accuracy and speed of performing the ongoing task.

The monitoring view predicts both costs to the ongoing task under all conditions and poor PM performance when there is no evidence of strategic monitoring. The spontaneous view predicts there should be no cost to the ongoing task under all conditions and that PM performance should not be highly related to costs on the ongoing task. By contrast, the multiprocess position assumes that people have a general bias to rely on a spontaneous retrieval process. However, they will develop a strategic monitoring approach to prospective remembering when the ongoing task does not encourage focal processing of the target event and when task instructions emphasize the importance of the PM task. Further, according to the multiprocess view, high-PM performance can be achieved with little or no cost to the ongoing task with a focal target.

\section{Method}

Design and participants. The design was a $2 \times 2 \times 2$ mixed factorial that included the between-subjects variables of type of target (focal, nonfocal) and PM instructions (moderate emphasis, high emphasis) and the within-subjects variable of presence of a PM task (no PM task, PM task). Participants were either general psychology students at Furman University who received course credit for participating or volunteers from the general student population who received US\$6.00 for participating. Twenty-four participants were randomly assigned to each of the four conditions, and participants were tested either individually or in groups of 2 .

Procedure and materials. Participants were first given instructions about the word-categorization ongoing task. For this task, participants were presented with word pairs and their task was to decide whether the lower case word on the right of the screen was a member of the category represented by the capitalized word on the left of the screen. Participants were instructed to press keys labeled $Y(G$ key) or $N$ ( $H$ key) to indicate a yes or no response, respectively, and to make their decisions as quickly as possible. The pair stayed on the screen until participants responded, and the response triggered presentation of the next pair. Next, participants were given three practice trials and the opportunity to ask questions.

The experiment consisted of two halves, and each half consisted of eight blocks of word pair trials with 24 word pairs in each block. Two word-pair sets were created (each with 192 word pairs) with the Battig and Montague (1969) norms, and each set was used for one half of the experiment. The order of the word pairs in each set was fixed. The word sets were counterbalanced across both halves of the experiment. For one half of the experiment, participants performed only the word-categorization ongoing task. For the other half of the experiment, participants performed a PM task along with the ongoing task. For the PM task, participants were asked to press the slash key on the computer whenever the target item occurred. They were further told not to worry about performance on the ongoing task on that trial and to press the key whenever they remembered, even if remembering occurred several trials later. Participants received either highor moderate-importance PM instructions with the difference between the two conditions lying in the amount of emphasis placed on the PM task relative to the ongoing task. In the moderate-importance condition, participants were told that "we have a secondary interest in your ability to remember to perform an action in the future." They were further instructed that their main goal was to make the category decisions as quickly and as accurately as possible. In the high-importance condition, participants were told that they should perform the ongoing task as quickly and as accurately as possible but that they should in addition "concentrate on looking for" the target word. They were told that "it is very important that you consider your main goal in this section to find absolutely every occurrence of the target item."

The target item occurred four times in the PM half of the experiment and zero times in the control half of the experiment. Participants in the focal condition received a single target item (dormitory, history, tornado, or tortoise) with one quarter of the participants receiving one of the target items. Participants in the nonfocal conditions were asked to press the slash key whenever they saw the syllable tor, which for all participants occurred four times, once in each of the words dormitory, history, tornado, and tortoise. Our concern here was to keep the target event constant across all trials for both conditions (i.e., the same word in the focal condition and the same syllable in the nonfocal condition). The decision to have the nonfocal target occur in four different words was made to prevent participants from associating the syllable with a word, thereby functionally converting the nonfocal target into a focal target. For both the focal and nonfocal conditions, the target items appeared in the first, third, sixth, and seventh blocks within the PM half of the experiment. After participants received their instructions for the PM task, they were asked to repeat them back to the experimenter.

The order of performing the prospective and control halves of the experiment was counterbalanced, with half of the participants receiving each order. Participants who performed the PM half of the experiment first were given PM instructions prior to the first half of trials and then told not to perform the PM task during the second half of the experiment. Participants who received the PM task second were given the PM instructions prior to the second half of the experiment. After completing the experiment, participants filled out a brief questionnaire that tested their recall of the intended action and their recall and recognition memory for the target item (the target item was randomly mixed with four foils that had appeared in the ongoing task).

\section{Results}

$P M$. The rejection level for all analyses was set at .05 , and effect sizes were estimated using partial eta squared. A PM response was scored as correct if the participant pressed the slash key either during a presentation of the PM target or within one word pair following the target. Ninety-five percent of the PM responses were made within these initial two items and this is consistent with previous research (Einstein \& McDaniel, 1990), showing that participants tend to respond quickly or not at all.

The proportion correct values were included in a $2 \times 2$ betweensubjects analysis of variance (ANOVA), with type of target (focal, nonfocal) and PM instructions (moderate emphasis, high emphasis) as variables. PM performance was significantly higher with a focal target $(M=0.90, S D=0.16)$ than with a nonfocal target $(M=0.67, S D=0.33), F(1,92)=20.03, M S E=0.06, \eta^{2}=.18$. Also, high emphasis on the PM task $(M=0.87, S D=0.22)$ produced higher performance than did moderate emphasis on the PM task $(M=0.70, S D=0.32), F(1,92)=10.41, M S E=0.06$, $\eta^{2}=.10$. There was a reliable interaction between these two variables, $F(1,92)=5.73, M S E=0.06, \eta^{2}=.06$. Consistent with the results of Kliegel, Martin, McDaniel, and Einstein (2004), emphasizing the PM task did not improve PM performance with a 
focal target $(F \mathrm{~s}<1 ; M \mathrm{~s}=0.88$ and $0.92, S D \mathrm{~s}=0.16$ in the moderate- and high-emphasis conditions, respectively), but it did with a nonfocal target, $F(1,92)=15.90, M S E=0.06, \eta^{2}=.13$ $(M \mathrm{~s}=0.53$ and $0.81, S D \mathrm{~s}=0.34$ and 0.27 , in the moderate- and high-emphasis conditions, respectively).

When queried at the end of the experiment, $100 \%$ of the participants correctly recalled the PM action (pressing the slash key). Also, all but 2 participants (both in the focal target condition) correctly recalled the target item, and these 2 participants correctly recognized the target item. Thus, it seems likely that the PM failures described above were due to problems in retrieving the intended action when the target occurred (i.e., PM problems) rather than to poor RM for the task demands.

Ongoing task performance. The goal of this section is to examine whether performing a PM task affected the accuracy and speed of performing the ongoing task. Because performance on the ongoing task could have been contaminated by thoughts about having performed the PM task, our strategy was to tabulate performance on the PM half of the experiment by using only those blocks in which there were no PM targets (Blocks 2, 4, 5, and 8). The corresponding four blocks were used from the non-PM half of the experiment. Because each block was composed of 24 trials, we computed accuracy and speed scores over 96 trials for the PM half and 96 trials for the non-PM half.

Initially, we computed the proportion of items correctly categorized, and these were included in a $2 \times 2 \times 2$ mixed ANOVA that contained the between-subjects variables of type of target (focal, nonfocal) and PM instructions (moderate emphasis, high emphasis) and the within-subjects variable of presence of the PM task (no PM task, PM task). Consistent with previous research (Marsh, Hicks, Cook, Hansen, \& Pallos, 2003; Smith, 2003), there was no effect of performing a PM task on the accuracy of performing the ongoing task $(M \mathrm{~s}=0.97, S D \mathrm{~s}=0.02$ in both the no PM and PM conditions), $F(1,92)=1.48, p=.29$. Also, there were no significant effects involving this variable (all $p \mathrm{~s}>.16$ ).

We next examined response times for performing the ongoing task. We tabulated the mean response time on correctly answered trials (over Blocks 2, 4, 5, and 8) in the PM and non-PM halves of the experiment. Outliers $(3.97 \%$ of the response times) were trimmed by removing response times that were more than two standard deviations from the mean (Einstein, McDaniel, Williford, Pagan, \& Dismukes, 2003; Ratcliff, 1979). These means were

Table 1

Mean Response Times (in Milliseconds) on the Ongoing Task as a Function of the Type of Target, PM Emphasis Instructions, and Presence of a PM Task in Experiment 1

\begin{tabular}{crrrrr}
\hline & \multicolumn{2}{c}{ Moderate emphasis } & & \multicolumn{2}{c}{ High emphasis } \\
\cline { 2 - 3 } \cline { 5 - 6 } Target & No PM task & PM task & & No PM task & PM task \\
\hline Focal & & & & \\
$M$ & $1,073.25$ & $1,120.87$ & & $1,149.25$ & $1,239.17$ \\
$S D$ & 112.04 & 116.48 & & 137.58 & 175.42 \\
Nonfocal & & & & & \\
$M$ & $1,140.92$ & $1,425.39$ & & $1,183.17$ & $1,593.43$ \\
$S D$ & 172.87 & 378.52 & & 164.43 & 300.86 \\
\hline
\end{tabular}

Note. $\mathrm{PM}=$ prospective memory. included in a $2 \times 2 \times 2$ mixed ANOVA like the one described above. As can be seen in Table 1, response times were slower with a nonfocal target $(M=1,335.73)$ relative to a focal target $(M=$ $1,145.63), F(1,92)=22.87, M S E=75,851.54, \eta^{2}=.20$, and response times were slower in the high-emphasis $(M=1,291.26)$ condition relative to the moderate-emphasis condition $(M=$ $1,190.11), F(1,92)=6.47, M S E=75,851.54, \eta^{2}=.07$. In terms of examining the cost of performing a PM task on ongoing task performance, participants performed the ongoing task more slowly when they were also performing the PM task, $F(1,92)=131.66$, $M S E=15,783.85, \eta^{2}=.59($ see Table 1$)$

It is important to note that this main effect was qualified by interactions such that (a) nonfocal targets $\left(M_{\text {cost }}=347.37 \mathrm{~ms}\right)$ produced greater cost to the ongoing activity than did focal targets $\left(M_{\text {cost }}=68.77 \mathrm{~ms}\right), F(1,92)=59.01, M S E=15,783.85, \eta^{2}=$ .39 , and (b) instructions with high-PM emphasis $\left(M_{\text {cost }}=250.09\right.$ $\mathrm{ms})$ produced greater cost than did moderate-emphasis instructions $\left(M_{\mathrm{cost}}=166.05 \mathrm{~ms}\right), F(1,92)=5.37, M S E=15,783.85, \eta^{2}=$ .06 . The three-way interaction was not significant, $F(1,92)=$ $1.26, p=.27$.

Finally, to examine the theoretical issues outlined earlier, we computed planned comparisons contrasting response times with and without a PM task for each of the between-subjects conditions to identify precisely under what condition(s) significant costs occurred. The PM task did not produce a significant cost to the ongoing activity in the focal target moderate-emphasis condition $\left(M_{\text {cost }}=47.62 \mathrm{~ms}\right), F(1,92)=1.73, p=.19$. There were significant costs in the focal target high-emphasis condition $\left(M_{\text {cost }}=89.92 \mathrm{~ms}\right), F(1,92)=6.15, M S E=15,783.85, \eta^{2}=.06$, the nonfocal moderate-emphasis condition $\left(M_{\text {cost }}=284.47 \mathrm{~ms}\right)$, $F(1,92)=61.52, M S E=15,783.85, \eta^{2}=.40$, and in the nonfocal high-emphasis condition $\left(M_{\text {cost }}=410.26 \mathrm{~ms}\right), F(1,92)=127.96$, $M S E=15,783.85, \eta^{2}=.56$. As can be seen, the effects of type of target and instructions were additive such that the greatest cost to the ongoing task occurred with a nonfocal target and highemphasis instructions.

\section{Discussion}

Contrary to the predictions of both the strategic monitoring and the reflexive associative views, the results indicated that people rely on different processes under different conditions. Thus, the results support the multiprocess predictions that the nature of the target event and the instructional emphasis on the PM task affect participants' strategies. As evidenced by the lack of significant costs (both in the accuracy and speed of performing the ongoing task) associated with performing a PM task, participants relied on spontaneous retrieval processes with a focal target event and moderate-emphasis instructions. There were, however, significant costs in the other conditions suggesting that participants relied on strategic monitoring with a nonfocal target or high-emphasis instructions or both.

The multiprocess view is also useful for understanding the effects of the different manipulations on PM performance. High emphasis instructions led to greater monitoring for the PM target, as evidenced by greater costs on the ongoing task relative to moderate-emphasis instructions. This increased monitoring had minimal and nonsignificant effects on PM with a focal target, probably because spontaneous processes were sufficient to yield 
high performance. With nonfocal targets, however, strategic monitoring benefited PM performance because spontaneous processes are assumed to be relatively ineffective with this type of target event.

An important additional result is that participants in the focal target moderate-emphasis condition had very high PM performance (nearly at ceiling), despite showing no significant costs on the ongoing task. According to Smith's (2003) monitoring theory (we consider other views of monitoring in the General Discussion), there should be no prospective responding in the absence of a capacity consuming process that initiates a recognition check for each item. This pattern suggests that PM retrieval can occur spontaneously under certain conditions.

\section{Experiment 2}

In the next experiment, participants performed the wordcategorization ongoing task and the focal and nonfocal PM tasks used in Experiment 1, and all participants received moderateemphasis instructions. The major change in this experiment is that we randomized the order of presenting word pairs for each participant, and this allowed us to evaluate performance across the course of the experiment without possible contamination of item effects.

According to the multiprocess view, the task parameters are critical for determining whether participants rely on monitoring or on spontaneous retrieval processes. One important task variable may be the length of the delay over which participants must maintain an intention. Following from Bargh and Chartrand's (1999) view that people have a limited capacity for conscious control over behavior, it may be difficult to maintain a monitoring process over an extended period of time (but see Maylor's [1996] PM results across trials). Thus, as the length of the delay increases there should be less evidence of monitoring.

According to the monitoring view, these predicted decreases in monitoring over trials should be accompanied by lower prospective remembering in both the focal and nonfocal conditions. According to the multiprocess view, however, reduced levels of monitoring over trials should be associated with reduced PM in only those conditions in which monitoring is essential for PM retrieval (i.e., a nonfocal target). By contrast, with a focal target, when we generally expect little monitoring and yet high PM through spontaneous retrieval, any reduction in monitoring over the course of the experiment should have little, if any, effect on PM.

\section{Method}

Design and participants. The $2 \times 2 \times 4$ mixed factorial design included the between-subjects variable of type of target (focal, nonfocal) and the within-subjects variables of presence of a PM task (no PM task, PM task) and trials. The 24 participants in each of the two conditions were volunteers from the student population and received US\$8.00 for participating. Participants were tested individually or in groups of 2 .

Procedure and materials. As in Experiment 1, participants performed word categorization as the ongoing task and they were to press a designated key (in this case, the $Q$ key) whenever they saw a PM target item. The major change was that we randomly determined the order of the word pairs for each participant. This enabled us to neutralize item effects in examining costs and PM performance across the course of the experiment. In terms of the ongoing task, we reversed the order of the items within a word pair such that participants decided whether the lowercase word on the left side of the screen was a member of the category represented by the capitalized word on the right. We shortened the number of pairs of items to 160 (plus 5 filler items at the end) for the PM half and 160 pairs for the control half. The two sets of 160 pairs were used equally often in the PM and control halves of the experiment.

For the PM task, half of the participants received a focal target item and the other half received a nonfocal target item. The focal target was either the word dormitory or tornado and each was a target (presented four times) for half of the participants. The nonfocal target was the syllable tor, and it occurred four times, once in each of the words dormitory, tornado, history, and tortoise. For both the focal and the nonfocal conditions, the target item appeared on the 40th, 80th, 120th, and 160th trials within the PM half of the experiment. For the nonfocal condition, the order of the four words containing the target syllable was randomly determined.

In order to reinforce the importance of performing the ongoing task quickly, we modified the instructions and practice trials. Participants who performed the PM half of the experiment first were initially given instructions about the word-categorization task and then 6 practice trials. Next, we emphasized that their main task was to perform the ongoing task as quickly as possible. Participants were then given 11 practice trials with feedback in the form of accuracy and response time following each response. Next, participants were given the moderate emphasis PM instructions used in Experiment 1 and were then asked to repeat the entire task demands to the experimenter. They were then given another set of 11 practice trials (with no feedback) with the PM target word appearing as the sixth item. Participants who received the PM task in the second half of the experiment were given the PM instructions along with the 11 practice trials containing the PM target prior to the second half of trials. Between the two halves of the experiment, participants completed a demographics questionnaire and the Mill Hill Vocabulary Test (Raven, 1965).

\section{Results}

$P M$. PM was scored, for each of the four trials individually, with a 0 or 1 depending on whether participants correctly responded to the PM target. As in Experiment 1, a response was scored as correct if the participant responded during either the presentation of the PM target or the following pair. Less than $1 \%$ of the responses occurred at other times.

These scores were included in a $2 \times 4$ mixed ANOVA that included the between-subjects variable of type of target (focal, nonfocal) and the within-subjects variable of trials. PM performance was significantly higher with a focal target $(M=0.93, S D$ $=0.16)$ than with a nonfocal target $(M=0.61, S D=0.32), F(1$, $92)=18.38, M S E=0.26, \eta^{2}=.17$, and generally declined from the first to the last trial, $F(3,138)=2.99, M S E=0.12, \eta^{2}=.06$. Although the interaction between trials and type of target was not significant, $F(3,138)=1.26, p=.29$, examination of the means across trials indicated a pattern of decrease in the nonfocal condition $(M \mathrm{~s}=0.71,0.71,0.63,0.42, S D \mathrm{~s}=0.46,0.46,0.50,0.50$ respectively) but little variation in the focal condition $(M \mathrm{~s}=0.92$, 0.96, 0.96, 0.88, SDs $=0.28,0.20,0.20,0.34$, respectively). Planned comparisons confirmed that the decline in prospective remembering from the first to the last trial was reliable in the nonfocal condition, $F(1,138)=8.76, M S E=0.12, \eta^{2}=.06$, but not in the focal condition $(F<1)$.

In postexperimental questioning, $100 \%$ of the participants remembered the correct PM action, and 90\% recalled the target item. This latter figure probably underestimates memory for the target because participants in the nonfocal condition were mistakenly 
asked to list the target "word." The fact that all but 1 participant performed the PM task on at least one trial is further indication that participants understood and remembered the task demands.

Ongoing task performance. To examine whether performing a PM task affected the accuracy and speed of performing the ongoing task across trials, we first divided the 160 ongoing trials into quarters. We tabulated performance on the 39 word pairs between each of the target occurrences after excluding the first 5 word pairs (in order to allow the response times to stabilize) and the 5 word pairs following each target (to remove influences of possible ruminations about the PM task following the occurrence of the target). Thus, the accuracy and response time data were based on 34 pairs from each quarter of the list.

The accuracy data were analyzed in a $2 \times 2 \times 4$ mixed ANOVA that included the between-subjects variable of type of target (focal, nonfocal), and the within-subjects variables of presence of the PM task (no PM task, PM task) and trial block. As in the first experiment, the proportion of items correctly categorized was high $(M=$ $0.96, S D=0.03)$ and did not vary significantly across conditions (all $p \mathrm{~s}>$.26).

We next examined response times to determine whether performing a PM task exacted a cost on the speed of performing the ongoing task. Outliers were again trimmed by using the method described in Experiment 1, and this eliminated $3.82 \%$ of the response times. The resulting mean response times were included in the $2 \times 2 \times 4$ mixed ANOVA defined earlier. As can be seen in Table 2, participants were slower to categorize items when they were also performing a PM task, $F(1,46)=33.15, M S E=$ $37,489.84, \eta^{2}=.42$. Importantly, and consistent with the results of Experiment 1, this effect interacted with the type of target, $F(1$, 46) $=18.32, M S E=37,489.84, \eta^{2}=.28$. Planned comparisons revealed that the cost of performing a PM task was significant in the nonfocal condition $\left(M_{\text {cost }}=198.36\right), F(1,46)=50.38, M S E=$ $37,489.84, \eta^{2}=.52$, but not in the focal condition $\left(M_{\text {cost }}=29.18\right)$, $F(1,146)=1.08, p=.30$.

It is interesting to note that there was a main effect of trials, $F(3$, $138)=4.33, M S E=30,182.33, \eta^{2}=.09$, and this was qualified

Table 2

Mean Response Times (in Milliseconds) on the Ongoing Task as a Function of the Type of Target, Presence of a PM Task, and Trials in Experiment 2

\begin{tabular}{|c|c|c|c|c|}
\hline \multirow[b]{2}{*}{ Trial } & \multicolumn{2}{|c|}{ Focal } & \multicolumn{2}{|c|}{ Nonfocal } \\
\hline & No PM task & PM task & No PM task & PM task \\
\hline \multicolumn{5}{|l|}{1} \\
\hline$M$ & $1,108.76$ & $1,160.54$ & 969.02 & $1,240.36$ \\
\hline$S D$ & 203.35 & 195.68 & 116.40 & 215.61 \\
\hline \multicolumn{5}{|l|}{2} \\
\hline$M$ & $1,122.50$ & $1,096.72$ & 971.36 & $1,190.24$ \\
\hline$S D$ & 171.40 & 136.01 & 124.89 & 205.00 \\
\hline \multicolumn{5}{|l|}{3} \\
\hline$M$ & $1,096.18$ & $1,175.57$ & 957.19 & $1,122.55$ \\
\hline$S D$ & 155.22 & 248.35 & 119.83 & 172.26 \\
\hline \multicolumn{5}{|l|}{4} \\
\hline$M$ & $1,108.99$ & $1,120.33$ & 952.68 & $1,090.58$ \\
\hline$S D$ & 203.15 & 170.92 & 112.84 & 185.73 \\
\hline
\end{tabular}

Note. $\mathrm{PM}=$ prospective memory. by interactions with type of target, $F(3,138)=3.38, M S E=$ $30,182.33, \eta^{2}=.07$, and with the presence of the PM task, $F(3$, $138)=3.66, M S E=27,472.51, \eta^{2}=.07$. Also, the three-way interaction was significant, $F(3,138)=3.71, M S E=27,472.51$, $\eta^{2}=.07$. As can be seen in Table 2, the main source of these interactions was that the cost of performing a PM task decreased across trials in the nonfocal condition but remained relatively stable in the focal condition. Performance across trials was fairly stable for both the nonfocal and the focal conditions when participants were not performing a PM task. Whereas the cost of performing a PM task on response times fluctuated somewhat haphazardly across trial quarters in the focal condition $\left(M \mathrm{~s}_{\text {cost }}=\right.$ $51.79,-25.78,79.39$, and 11.34, SDs $=189.69,117.56,264.69$, and 192.43 , respectively), the cost steadily decreased across trial quarters in the nonfocal condition $\left(M \mathrm{~s}_{\mathrm{cost}}=271.34,218.88\right.$, 165.36, and 137.90, SDs $=180.58,158.79,114.88$, and 178.70, respectively). Planned comparisons revealed a significant decrease in costs from the first to the final quarter in the nonfocal condition, $F(1,138)=7.08, M S E=27,472.51, \eta^{2}=.05$, but not in the focal condition $(F<1)$.

\section{Discussion}

In summary, the results supported the predictions of the multiprocess theory. As in Experiment 1, the nature of the target event determined whether participants adopted a strategic or spontaneous retrieval approach to the PM task. Also, in the focal condition, high PM performance was obtained with no significant costs to the ongoing task. An important new result was that monitoring declined over trials in the nonfocal target condition. This result is consistent with Smith's (2003) view that monitoring is a controlled process and with Bargh and Chartrand's (1999) view that capacity for maintaining controlled processing is limited. Critically, and as predicted by the multiprocess theory, decreased monitoring in the nonfocal condition was associated with declines in PM performance, whereas no such relation was observed in the focal condition.

\section{Experiment 3}

The results of Experiments 1 and 2 that showed no significant costs on the ongoing task with a focal target event are consistent with the findings of Marsh et al. (2003) who, through the use of a lexical decision ongoing task (like that of Smith, 2003), also found no costs with a focal target. On the surface, these results appear to conflict with those of Smith who found large costs with target events that were focal in nature. One potentially important difference between these studies is that Smith's participants were asked to perform a PM response whenever any of six possible target events occurred, whereas our experiments and the Marsh et al. experiment used a single target event. It seems likely that with complex PM demands (i.e., six target cues), participants are more apt to rehearse the target events or strategically monitor for them or both. Because there were many other differences between Smith's studies and ours (e.g., her lexical decision ongoing task produced a quicker response than our categorization task), we thought it important to directly compare costs on the cover task with one- and six-target events. Also, for the purpose of develop- 
ing generality across different cover tasks, we used a new sentence completion task in Experiments 3 and 4.

Another feature of Experiments 3 and 4 is that we used an ongoing task that should be highly sensitive to the presence of monitoring. Specifically, participants had to decide whether a capitalized word at the end of the sentence correctly fit into the blank in the sentence. The PM task was to press a key whenever a target item occurred anywhere among the 10-14 words in the sentence. If participants need to engage a resource-demanding monitoring process for each individual word in the sentence in order to detect a single target (as Smith \& Bayen's [2004] model proposes), then performing a PM task in addition to the ongoing task should produce robust costs. From the multiprocess view that participants rely on different processes for different task demands, we expected no costs with a single target and significant costs with six-target events.

\section{Method}

Participants and design. The design was a $2 \times 2$ mixed factorial, with number of target events (one, six) as the between-subjects variable and presence of the PM task (no PM, PM) as the within-subjects variable. Thirty-two participants were assigned to each of the two between-subjects conditions. Participants, who were tested individually or in pairs, were Furman University students who received course credit for participating.

Materials and procedure. The ongoing task consisted of sentencecompletion questions adapted from examples in Scholastic Assessment Test and Graduate Record Examination study guides. All sentences contained between 14 and 18 words. Initially, participants were instructed that their main task was to determine whether the word in capital letters at the end of each sentence correctly completed the blank in the sentence and to press the key labeled $Y$ ( $G$ key) to indicate yes or $N$ ( $H$ key) to indicate $n o$. The following is an example sentence: The warrior's armor makes him to any blows that he may undergo in battle. IMPERVIOUS.

Participants were advised to read the entire sentence before giving an answer and to make their decision as quickly and accurately as possible. They were then given 10 practice sentences and encouraged to ask any questions that they had about the task.

Each participant performed two sets of sentence-completion items (Set A and Set B) with 110 sentences in each set. The sentences were presented at a preprogrammed rate of $7.5 \mathrm{~s}$ per item. During the break between the two task sets, participants completed a demographics questionnaire and the Mill Hill Vocabulary Test (Raven, 1965). Half of the participants performed the PM task during Set A and the other half during Set B. We counterbalanced the order of performing Sets A and B and whether participants performed the PM task in the first or second set.

Participants who received the PM task first were presented with a screen containing PM instructions following their completion of the practice items. For the second set of trials, they were told that performing the sentence-completion task was their only demand. Those performing the PM task second were presented with the instruction screen following the break between the two tasks, right before they began their second set of items. For the PM set, participants were given the moderate-emphasis instructions used in Experiments 1 and 2. The response was to press the Enter key, and to ensure that participants knew the location of this key, they were asked to press the Enter key before proceeding. Participants were then asked to review the instructions for the experimenter at this point and misunderstandings were clarified.

All participants were told that the target word could occur anywhere in the sentence. In the one-target condition, participants were given a target word (evening, horse, medicine, or orange) to learn (each item was the target for one quarter of the participants). The target word for a particular participant occurred four times during the experiment and always in the 26th, 52nd, 78th, and 104th sentences. In the six-target condition, participants were presented the target words evening, horse, medicine, orange, sauce, and goggles. Only four of these words (evening, horse, medicine, and orange) actually occurred in the sentences, each occurring once, and they occurred in the same sentence locations as in the one-target condition. Participants did not know how many target items would appear in the sentences. To ensure that participants learned the target item(s), in both conditions we presented the target(s) on the computer monitor for as much time as needed, and then we tested their memory by asking them to write down the target item(s). Participants were then shown the target word(s) a second time (for an unlimited time) and again asked to write them down. All participants had perfect recall of the target(s) by the second trial. After completing the second task set, participants were given a questionnaire that tested their RM for the action they were to perform and for the target $\operatorname{item}(\mathrm{s})$.

\section{Results}

PM. A PM response was scored as correct if the participant performed the intended action during the sentence in which the target appeared or the following sentence. This measure captured 99\% of the PM responses. The proportion of correct PM responses (out of four possible) was tabulated and included in a single factor between-subjects ANOVA that compared the one-target and sixtarget conditions. PM performance was nominally but not significantly higher in the one-target condition $(M=0.80, S D=0.28)$ than in the six-target condition $(M=0.72, S D=0.25), F(1,62)=$ $1.38, p=.24$.

When queried at the end of the experiment, all participants remembered the PM action (i.e., pressing the Enter key). Participants in the one target condition recalled the target $100 \%$ of the time, and this was significantly higher than the $87.50 \%$ recall in the six-target condition, $F(1,62)=21.46, M S E=116.51, \eta^{2}=$ .26. Participants who did not recall all six target items were given a recognition test consisting of the six targets and six unrelated distractors and correctly recognized $96 \%$ of the targets. Thus, as in Experiment 1, there was good RM for the task demands. Even so, the nonsignificant difference in PM performance between the oneand six-target conditions could have been due to poorer RM for the target items in the six-target condition.

Ongoing task performance. To determine whether performing a PM task exacted costs on the ongoing task, we initially tabulated the proportion correct on the sentence task for the PM set and the non-PM set of sentences. We included only those sentences occurring after the first target event (which occurred in the 26th sentence). There were 25 sentences between each of the target occurrences, and we ignored performance on the 6 sentences following each target because we were concerned that there might have been heightened awareness of the PM task following the presentation of a target. Thus, the proportion correct measure was based on the remaining 19 sentences following each of the first three target events (for a total of 57 sentences). Only 6 sentences followed the fourth target event, and these were not included. The corresponding 57 sentences were selected for analysis from the sentence set for which no PM task was performed.

The proportion correct measure was submitted to a $2 \times 2$ mixed ANOVA that included the between-subjects variable of number of target events and the within-subjects variable of presence of a PM task. There was no effect of performing a PM task on the accuracy of performing the sentence completion task $(M \mathrm{~s}=0.69$ and 0.70 , $S D$ s $=0.10$ and 0.11 when not performing a PM task and when 
performing a PM task, respectively), $F(1,62)=1.26, p=.27$. No other effects were significant $(p s>.33$ ).

Next, we tabulated the mean response time for correct sentences after removing responses that were less than $1 \mathrm{~s}$ (occasionally participants were a bit slow and responded just after the 7.5-s presentation time to the prior sentence, and this was recorded as a very fast response to the next sentence) and responses greater than two standard deviations from the mean (Ratcliff, 1979). This procedure eliminated $3.06 \%$ of the responses. The time taken to respond to the sentences was significantly slower when participants were also performing a PM task, $F(1,62)=27.36, M S E=$ $50,861.52, \eta^{2}=.31$. The effect of number of targets was not significant, $F(1,62)=2.73, p=.10$. It is important to note that there was a reliable interaction between these two variables, $F(1$, 62) $=8.22, M S E=50,861.52, \eta^{2}=.12$. The slowing that occurred as a result of performing a PM task was larger in the six-target condition $(M=4,890 \mathrm{~ms}, S D=508 \mathrm{~ms}$ in the no PM condition; $M=5,212 \mathrm{~ms}, S D=422 \mathrm{~ms}$ in the PM condition; a difference of $322 \mathrm{~ms}$ ) than in the one-target condition $(M=4,791$ ms, $S D=618 \mathrm{~ms}$ in the no PM condition; $M=4,885 \mathrm{~ms}, S D=$ $591 \mathrm{~ms}$ in the PM condition; a difference of $94 \mathrm{~ms}$ ). These observations were confirmed by planned comparisons that indicated significant slowing in the six-target condition, $F(1,62)=$ $32.71, M S E=50,861.52, \eta^{2}=.35$, but no significant slowing in the one-target condition, $F(1,62)=2.78, p=.10, \eta^{2}=.04$.

\section{Discussion}

The results indicate that the number of target events affects how participants approach a PM task (cf., Marsh et al., 2003). The results replicated, with a new ongoing task, the findings of Experiment 1 and 2 and also of those of Marsh et al. (2003) showing that performance of a PM task with a single target does not produce significant costs on the accuracy and speed of performing the ongoing task. This failure to find effects on an ongoing task in which participants would need to monitor 14-18 items in each sentence for the target suggests that participants tend to rely on spontaneous retrieval processes with this type of task demand and importantly that monitoring is not necessary for high-PM performance. With six target events, however, there was a cost of performing a PM task, thereby suggesting a more controlled approach to prospective remembering. Moreover, the magnitude of the effect (in the range of $300 \mathrm{~ms}$ ) is very consistent with that found by Smith (2003).

\section{Experiment 4}

In line with our multiprocess view, the previous experiments have identified PM task characteristics that influence whether participants tend to adopt a resource-demanding monitoring process or rely on a spontaneous retrieval process to support PM. The multiprocess view also suggests that the particular PM processes recruited depends on individual preferences. Up to this point, however, the experimental literature has not focused on such individual preferences; indeed, prevailing methodologies do not allow determination of individual differences in processes underlying PM performances. The approach taken in the current study, which focuses on ongoing task costs, allows an objective method of identifying individual differences along the dimensions of in- terest here. Accordingly, in the present experiment we tested a large sample of participants with the sentence completion task from Experiment 3.

By using a large sample (104 participants), we were able to explore the degree to which individual differences may exist in the context of certain PM task parameters. Consider the findings in Experiments 1-3 of nonsignificant costs to the ongoing activity with a single focal target event. On the one hand, the nonsignificant costs could simply reflect random variation around a mean of zero. On the other hand, the small mean cost could reflect a mix of participant strategies. The possibility here is that some participants show relatively substantial costs and at levels in accord with those shown by groups under conditions appearing to stimulate monitoring. Other participants, by contrast, would clearly show no costs on the ongoing activity under PM instructions. Indeed this mix of strategies could be present even under conditions in which significant costs are obtained and in which researchers assume that the mean cost reflects a strategic monitoring process that is universal for all participants in the sample (cf. Smith, 2003).

\section{Method}

Design and participants. The within-subjects variable was presence of the PM task (no PM task, PM task). The 104 participants were undergraduates from psychology classes at the University of New Mexico who participated either for extra credit or for a research requirement for an introductory psychology class. Ten additional participants were tested but omitted from the analyses for various reasons, including failure to remember the target item or instructions, problems in understanding the instructions, and computer error.

Materials. Experimental stimuli were based on the 220 sentences used in Experiment 3. In an attempt to increase the number of correct responses, we tested 6 pilot participants and identified all sentences for which half of the participants produced incorrect responses. For these 56 sentences, we replaced the target word with a word whose meaning we judged to be more familiar. The sentences were grouped into two sets of 110 sentences and each sentence set was used equally often in the PM and control blocks, respectively, as well as equally often in terms of order of presentation.

Procedure. For purposes of generality, we tested half of the participants under a discrete trial procedure with trials separated by a $500-\mathrm{ms}$ fixation point in the middle of the screen. The sentence screen was then shown, and after participants made their response they had to press the spacebar to advance to the next screen. The other half of the participants were tested with a continuous trial condition in which there was no fixation point, and after the response, the next sentence screen automatically appeared. Because these procedural differences produced no effects in any of the initial analyses (all $p \mathrm{~s}>.13$ for critical latency analyses; $p s>.07$ for other analyses), we no longer mention them. All participants were tested in the one-target condition from Experiment 3. Other than these changes and the fact that presentation of the sentences was self-paced for half of the participants, the procedure of this experiment was identical to that used in Experiment 3.

\section{Results}

Ongoing task performance. Because a key aspect of the PM analysis involved using the ongoing task performance to illuminate possible individual differences in monitoring strategies versus spontaneous retrieval, we first report the analyses of ongoing task performance. The accuracy rate was virtually identical across the PM and the control blocks $(M=0.73, S D=0.10$ in the PM block, $M=0.74, S D=0.10$ in the control block). A within-subjects 
ANOVA confirmed that accuracy was not significantly affected by the presence of the PM task $(F<1)$.

As in the previous experiments, the mean response latencies for the correct trials with outliers $(6.01 \%$ of the trials) excluded were also submitted to a within-subjects ANOVA. Responses to the sentence completion task were significantly slower when the PM task was present $(M=7,167.87 \mathrm{~ms}, S D=1,638.49)$ than when it was not present $(M=6,975.96 \mathrm{~ms}, S D=1,506.64), F(1,103)=$ 4.36, $M S E=438,821.12, \eta^{2}=.04$.

To assess the potential cost of the PM task for each participant, we computed the difference in response latencies between the PM block and control block, after adjusting the latencies to reflect the presentation procedure and counterbalancing condition to which the participant was assigned. ${ }^{2}$ We identified participants who showed an increased average response latency for the PM versus the control block and those who did not show an increase. This analysis clearly revealed that there were substantial numbers of participants displaying both patterns. Fifty-eight participants had increased latencies for the PM block $\left(M_{\mathrm{PM}}=7,533.95, S D=\right.$ $\left.1,769.18 ; M_{\text {control }}=6,797.26, S D=1,484.68\right)$, whereas 46 participants showed decreased latencies for the PM block $\left(M_{\mathrm{PM}}=\right.$ 6,706.30, $\left.S D=1,337.78 ; M_{\text {control }}=7,201.28 ; S D=1,520.06\right)$. For this latter group, the decreased latencies in the PM block was not at the expense of accuracy of ongoing task responding for PM $(M=0.72, S D=0.10)$ versus control blocks $(M=0.73, S D=$ 0.09 ). A $2 \times 2$ mixed ANOVA with cost group (58 with increased latencies, 46 with decreased latencies) as the between-subjects variable and presence of PM task (PM block, control block) as the within-subjects variable confirmed that the groups did not differ in ongoing task accuracy, that there was no difference in accuracy as a function of block, and no interaction (all $F_{\mathrm{s}}<1$ ).

A possible issue in interpreting the above individual differences is that the tendency to display increased versus decreased latencies on the PM block relative to the control block might be linked to the order in which the two blocks were presented. There was, however, no association between whether participants displayed a cost in response latency for PM blocks and what block was presented first, $\chi^{2}(1, N=104)=.62$. It was also the case that there was no significant relation between whether participants displayed a cost and the overall response latencies (averaged across the two blocks) on the ongoing activity $(M \mathrm{~s}=7,166.00$ and $6,804.00, S D \mathrm{~s}=$ $1,581.79$ and $1,404.71$, for cost and no cost participants, respectively; $F<1$ ). Thus, having ruled out potential alternative differences between the cost versus no-cost participants, following the logic of this study such differences suggest that participants showing a cost on PM trials were likely recruiting monitoring strategies to accomplish the PM task. In contrast, participants showing no cost whatsoever would be assumed to not have engaged in monitoring. After the next section, we explore the relation between the recruitment of monitoring strategies and PM performance.

Ancillary analyses. Because a single difference score for a particular individual is not a precise index of whether that individual displayed a cost on the PM trials, we computed a $90 \%$ confidence interval for each participant's difference score (based on that participant's variability in response times). ${ }^{3}$ This analysis indicated that the confidence intervals for 74 participants either included zero or included only values representing decreasing latencies for PM trials relative to control trials. Thus, fewer than $30 \%$ of the participants could be confidently characterized as displaying increased latencies on PM trials; that is, they could be characterized as recruiting monitoring strategies.

$P M$. The average proportions of correct PM responses were tabulated as a function of cost group (as determined by the initial response latency analyses). PM performance was high for both the $\operatorname{cost}(M=0.95, S D=0.17)$ and no-cost $(M=0.94, S D=0.14)$ groups and was not significantly different $(F<1)$.

Finally, we used the confidence intervals to implement a strict criterion such that only those with confidence intervals above zero (increased latency on PM trials) were designated as the cost group $(n=30)$ and only those with confidence intervals below zero were designated as the no-cost group $(n=14)$. Again, the proportion of PM responses was high for both groups $(M=0.96, S D=0.15$, for the cost group; $M=0.91, S D=0.19$, for the no-cost group) and not significantly different $(F<1)$.

\section{Discussion}

The results indicate that the presence of an overall cost to the ongoing activity when performing a PM task does not necessarily reflect each individual's performance. For this experiment $56 \%$ of the participants carried the cost effect on the PM block. Thus, $44 \%$ of the participants in this experiment displayed a decrease in response latency for PM blocks. The implication is that nearly half (at least) of the participants were not recruiting monitoring to perform the PM task.

The second important finding was that the no-cost participants displayed very high PM performance that was not significantly different from that displayed by cost participants. This finding is at odds with the preattentive processes (monitoring) model of PM (Smith, 2003). On this view, the group of participants not displaying any evidence of monitoring should have failed to perform the PM task.

\footnotetext{
${ }^{2}$ To increase precision of the cost computing, for each individual we took into account the presentation procedure (continuous vs. discrete presentation, block order, and sentence set counterbalancing condition). Thus, we computed the average speed-up across blocks one and two when each sentence set (Set A or Set B) appeared first for each presentation procedure. For a particular participant, the value (speed-up) obtained for her or his presentation procedure and counterbalancing condition was added to her or his average latency for the second block of trials. Therefore, for every participant the difference between responses for PM and control blocks took into account the artifact of speed-up across blocks and the fact that this speed-up varied across counterbalancing conditions.

More generally, in Experiments 1-4, initial latency analyses included the counterbalancing variable of the order of the experimental blocks (PM, control). These analyses confirmed the necessity to counterbalance order, as performance significantly improved from the first to the second block of trials (except in Experiment 1). This effect interacted with the other experimental variables only in Experiment 2. In Experiment 2, the robust cost with the nonfocal target overrode the typical improvement from the first to the second block. In addition, in Experiments 1-4, the initial analyses included the counterbalancing variable of order in which the alternative materials sets (lists) were presented. In some cases (Experiment 2-4), material sets significantly modulated the magnitude of the difference in response times with and without a PM task (costs) but these effects did not enter into interactions with the other experimental variables. Thus, none of these counterbalancing orders qualify our conclusions.

${ }^{3}$ We thank David Meyer for this suggestion.
} 


\section{Experiment 5}

In Experiments 1-4, we inferred the existence of spontaneous retrieval whenever there were no costs to the ongoing task of performing a PM task and yet high PM performance. The goal of the present experiment was to provide direct evidence for the existence of spontaneous retrieval processes. An important characteristic of a spontaneous process is that it should occur without intention. The research strategy in the next experiment was to examine whether there is any evidence for PM retrieval when the PM intention is suspended. Toward that end, we interleaved a lexical decision task between the PM instruction and the ongoing task (imagery rating task) in which participants expected the PM target cue. During the lexical decision task, participants were to ignore the PM task and simply respond as quickly as possible. Thus, there was no PM intention during the lexical decision task, and there should have been no monitoring of the items for the PM target. For control purposes, we included a condition that had a RM demand rather than a PM demand.

According to Smith's (2003) view that preparatory attentional processes are needed for PM retrieval, there should be no retrieval of the PM intention during the intervening lexical decision task. PM targets should be processed at least as quickly, if not more so, as neutral items. This expectation of faster processing for PM targets is based on the Marsh et al. (2002) finding that participants' reaction times on a lexical decision task to missed PM targets (i.e., trials on which participants forgot to perform the intended action) were faster than to matched neutral items. Their interpretation of this finding was that PM targets are maintained in memory at a higher level of activation, are more easily revived, or both.

By contrast, the spontaneous retrieval view predicts that presentation of a PM target, even in a context for which there is no intention to perform the PM task should trigger retrieval processes and these should slow down (interfere with) the speed of making a lexical decision. The Marsh et al. (2002) participants, when performing a lexical decision task, decided that PM target events were words more slowly (on successful PM trials) than they decided on neutral words. This pattern occurred even when participants were told to make their lexical decision response before the PM response. Marsh et al. interpreted this effect to mean that the slowed lexical decisions were due to cognitive processes associated with noticing the cue, retrieving the intention, and coordinating a PM response. Marsh et al. have shown that this slowing occurs when participants are intending to perform the PM task. Our interest in the present experiment was whether participants would demonstrate slowing associated with some of these processes under conditions of a suspended intention.

\section{Method}

Participants and design. The participants, who were tested individually or in groups of 2-6, were 72 Furman University undergraduate students who received course credit for participating. The design was a $2 \times$ 3 within-subjects factorial in which we varied type of memory task (RM, PM) and type of item in the lexical decision task (target, previously presented, and neutral). The main dependent measure was the response latency to these critical words.

Procedure. For one block of 10 trials, participants received PM instructions and for the other block, they received RM instructions. The order of performing these blocks was counterbalanced across participants. As shown in Table 3, a trial consisted of (a) presentation of a target item (which, depending on the block, was central to the PM or the RM task), (b) rating seven items for imagery, (c) making lexical decisions for 18 items, and (d) rating seven additional items for imagery. To highlight the target item, it was presented in red letters on a black background (the other materials appeared in white letters on black background). It is important to note that participants were told to suspend all demands involving the target during the lexical decision task and that during this task, their sole demand was to make their lexical decisions as quickly and as accurately as possible.

Participants were initially told that their main task was to rate the ease of imaging words on a scale from 1 (easy to image) to 3 (difficult to image). The rating scale along with the label for the anchors were printed below each word and participants used the 1-3 keys on the number pad to indicate their response. This task was experimenter paced, and the word and rating scale remained on the screen for $2.5 \mathrm{~s}$ before the next word appeared. Participants were given 12 practice trials.

Participants were then told that they would switch to a lexical decision task in the middle of performing the word-rating task. Participants were told that a string of letters would appear in the middle of the computer screen and they should decide as quickly as possible whether the letters formed a word. A 500-ms fixation point in the center of the computer monitor preceded each item. The item disappeared when the participant responded and was followed by a 200-ms delay before the next fixation point appeared. Participants indicated their response by pressing keys labeled $Y$ or $N$ (which were the 5 and 6 keys on the number pad, respectively). We emphasized to participants that whenever they were presented with this task, they should ignore all other task demands and respond as quickly as possible. To encourage quick responding on this task, participants were told to aim for making a response within 500-800 ms. They then received 20 practice trials (consisting of 10 words and 10 nonwords) with feedback about accuracy and speed of responding on each trial.

For the RM block of trials, participants were told that they would sometimes be tested for their recognition of the target item. On 4 of the 10 trials during the RM block of trials, participants received a recognition screen in which they were presented with an item and asked to indicate (by pressing the $Y$ or $N$ labeled keys) whether that item was the target item. On two trials it was the target word and on the other two trials it was a distracter word. For the first 36 participants, the recognition screen was presented for $2.5 \mathrm{~s}$. An analysis of these data indicated that participants often did not have enough time to respond within this brief period. Thus, we allowed the other 36 participants to take as long as needed to make their recognition judgment.

For the PM block of trials, participants were asked to press a designated key $(Q)$ on the keyboard if they ever saw the target again in the context of

Table 3

Sequence of Tasks in Experiment 5

\begin{tabular}{cc}
\hline PM block (10 trials) & RM block (10 trials) \\
\hline Target item presented for $2.5 \mathrm{~s}$ & Target item presented for $2.5 \mathrm{~s}$ \\
Imagery rating for 7 items ${ }^{\mathrm{a}}$ & Imagery rating for 7 items ${ }^{\mathrm{a}}$ \\
Lexical decision task & Lexical decision task \\
9 words and 9 nonwords, & 9 words and 9 nonwords, \\
including 3 critical words & including 3 critical words \\
Target-PM target & Target-RM target \\
Previously presented & Previously presented \\
Neutral & Neutral \\
Imagery rating for 7 items & Imagery rating for 7 items \\
\hline
\end{tabular}

Note. $\mathrm{PM}=$ prospective memory; $\mathrm{RM}=$ retrospective memory.

${ }^{\mathrm{a}}$ Items were presented for $2.5 \mathrm{~s}$ each and participants rated the case of forming an image.

${ }^{\mathrm{b}}$ The target word occurred during the second set of imagery ratings on 4 of the 10 blocks. 
the word-rating task. The target word occurred on 4 of the 10 trials in the PM block (during word rating).

Next, we summarized the tasks and reminded participants that their sole demand during the lexical decision task was to perform the lexical decision task as quickly as possible. Participants were then asked to describe the task requirements to the experimenter, and misunderstandings were clarified. This was done individually with participants at their cubicle. Next, participants performed a practice trial that included all phases (including the appearance of a target during the imagery rating task). They then had the opportunity to ask questions.

Participants had a 3-min break between the PM and RM blocks of trials. Following the break, participants were given the new instructions regarding the PM or RM tasks, asked to summarize them, given a complete practice trial, and given the opportunity to ask any questions.

Materials. For the imagery rating task, 14 items appeared on each trial (for a total of 280 items). Seven of the items preceded the lexical decision task and seven followed the lexical decision task. These were familiar words chosen from the Toglia and Battig (1978) norms (Clusters 2-8) on the basis of varying on concreteness.

There were 18 items in each lexical decision trial, and these consisted of nine words and nine nonwords. Included among these items were three critical words that were matched on number of letters, number of syllables, and familiarity (Toglia \& Battig, 1978). One of these items was the target event, another was a previously presented item (one that had occurred among the 7 items rated for imagery on that task) and another was a neutral item (one that had not been presented in the experiment). These 3 items were counterbalanced across participants such that each item served as a target item, previously presented item, and control item for an equal number of participants. The 180 nonwords were selected from the ARC nonword database (Rastle, Harrington, \& Coltheart, 2002) with the conditions that they were pronounceable, eight letters or fewer, and a maximum of two syllables. These items were counterbalanced across the PM and RM halves of the experiment.

\section{Results}

$P M$ and RM performance. We measured PM performance by tabulating the proportion of times (out of four possible opportunities) that participants remembered to press the $Q$ key when the target word occurred during the imagery-rating task. RM performance was measured by the proportion of times (out of four possible opportunities) that participants made a correct decision on the prompted-recognition test during the imagery-rating task. Somewhat surprisingly, performance on the recognition task $(M=$ $0.74, S D=0.23$ ) was not significantly higher than on the PM task $(M=0.76, S D=0.26)(F<1)$. Because halfway through the experiment we changed the procedure to allow participants to take as much time as needed to make their recognition judgments on the targets, we tabulated these responses separately for the first 36 participants and the last 36 participants. Whereas the means for the first and second half of the participants were identical for the PM task (both $M \mathrm{~s}=0.76, S D \mathrm{~s}=0.26)$, the later participants $(M=$ $0.81, S D=0.18)$ scored significantly higher than the early participants $(M=0.68, S D=0.26)$ on the RM task, $F(1,70)=5.48$, $M S E=0.05, \eta^{2}=.07$.

Accuracy on the lexical decision task. Lexical decisions were highly accurate $(M$ proportion correct $=0.96)$. We tabulated accuracy separately for each type of word and each block of the experiment and included these in a $2 \times 3$ within-subjects ANOVA. This analysis included the variables of type of memory task (RM, PM) and type of item in the lexical decision task (target, previously presented, and neutral). Participants were roughly equal in their lexical decision accuracy in the PM and RM blocks of the experiment $(F<1)$. Although the means for target, previously presented, and neutral items were similar $(M \mathrm{~s}=0.98,0.98,0.96$, $S D \mathrm{~s}=0.05,0.04,0.07$, respectively $)$, this effect was reliable, $F(2$, $142)=6.11, M S E=0.003, \eta^{2}=.04$. This finding indicated that participants were more accurate for items that they had seen before (either as a target item or as an item that had been rated for imagery). The interaction between these two variables was not significant $(F<1)$.

Response times on the lexical decision task. Next, we tabulated the mean response time for correctly identified words in the lexical decision task. After trimming responses greater than two standard deviations from the mean $(4.33 \%$ of the responses), we included the mean response times in the $2 \times 3$ within-subjects ANOVA described above. This analysis revealed reliably faster response times for the RM block than for the PM block, $F(1$, $142)=9.24, M S E=4,857.93, \eta^{2}=.06$ (see Table 4). There was also a significant effect of type of item, $F(2,142)=22.60, M S E=$ $3,107.38, \eta^{2}=.24$, reflecting fastest responding for previously presented items (due to repetition priming) and slowest responding for target items. It is important to note that these effects were qualified by a reliable interaction between these two variables, $F(2,142)=3.72, M S E=2,143.14, \eta^{2}=.05$. We examine the source of this interaction below.

Despite our instructions to ignore the PM task during the lexical decision task, it is possible that participants were unwilling or unable to turn off the monitoring process in this phase of the trials. To examine whether participants were monitoring, we performed a planned comparison testing for a difference in the speed of responding to neutral items in the PM and RM blocks. As can be seen in Table 4, response times for neutral words were not significantly higher $(F<1)$ in the PM block relative to the RM block. Also, response times for previously presented words were not significantly higher in the PM block than in the RM block $(F<1)$. For maximum power, we performed this comparison using both the neutral and previously presented items and again found that response times were not slower in the PM block, $F(1,71)=2.08$, $p=.15$. The fact that there was no reason to monitor in the RM block, along with the finding that the response times in the PM block were similar to those in the RM block, strongly indicates that participants were not monitoring for the PM target item during the lexical decision task.

Table 4

Mean Lexical Decision Response Times (in Milliseconds) as a Function of the Type of Task and the Type of Item in Experiment 5

\begin{tabular}{cccr}
\hline & \multicolumn{3}{c}{ Type of item } \\
\cline { 2 - 4 } $\begin{array}{c}\text { Type of } \\
\text { task }\end{array}$ & Target & $\begin{array}{c}\text { Previously } \\
\text { presented }\end{array}$ & Neutral \\
\hline PM & & & \\
$M$ & 631.13 & 576.50 & 603.94 \\
$S D$ & 133.19 & 87.43 & 92.02 \\
RM & & & \\
$M$ & 593.78 & 562.18 & 594.46 \\
$S D$ & 119.16 & 74.03 & 83.61 \\
\hline
\end{tabular}

Note. $\mathrm{PM}=$ prospective memory; $\mathrm{RM}=$ retrospective memory. 
Because participants were not monitoring, it makes sense to examine whether there was evidence for spontaneous retrieval when a target item occurred. Given that there was repetition priming for the previously presented items and that the target item also occurred previously in the trial, previously presented items seem to be the most appropriate control items from which to examine spontaneous retrieval associated with the target items. Thus, we performed a $2 \times 2$ ANOVA in which we included the variables of type of memory task (RM, PM) and type of item (target, previously presented). This analysis revealed slower lexical decisions for the PM block relative to the RM block, $F(1$, 71) $=9.95, M S E=4,832.80, \eta^{2}=.12$ (see Table 4). Also participants were significantly slower in responding to target items relative to previously presented items, $F(1,71)=31.92, M S E=$ 4,192.62, $\eta^{2}=.31$. This latter result indicates the existence of spontaneous retrieval when target events occurred. It is interesting to note that there was a reliable interaction between these two variables, $F(1,71)=5.77, M S E=1,654.54, \eta^{2}=.08$. As can be seen in Table 4, there was greater slowing (relative to previously presented items) for PM targets $(M=54.63 \mathrm{~ms})$ as compared with retrospective targets $(M=31.60)$. Thus, it appears that there is some spontaneous retrieval when retrospective targets are processed and even more when PM targets are processed.

\section{Discussion}

The results of this experiment provide direct evidence for the existence of spontaneous retrieval processes. Given the instructions to ignore the PM task and simply to focus on responding as quickly and accurately during the lexical decision task, there was no need to monitor for the target item while making lexical decisions in the PM block. Indeed, the virtually identical response times to neutral items in the prospective and RM blocks verify that participants were not monitoring for PM targets during the lexical decision task. With the previously presented item as a baseline, participants were slower to decide that RM targets were words and even slower to decide that PM targets were words. Marsh et al. (2002) found slowed lexical decisions, by about $300 \mathrm{~ms}$, to PM targets relative to control items when, unlike in our study, participants were instructed to perform the PM task during the lexical decision task (in some conditions after making a lexical decision). Their interpretation was that the longer latencies were due to noticing of the target, retrieval of the intention, and coordination of the execution of the ongoing task and PM actions. We observed slowing of approximately $32 \mathrm{~ms}$ for RM targets and $55 \mathrm{~ms}$ for PM targets, and our interpretation of these effects is that spontaneous retrieval occurred with both types of target items. Following the Marsh et al. description of processes, perhaps participants simply noticed the familiar target when it occurred (i.e., retrieved that it was a target). For PM targets, however, perhaps they retrieved the intended action (cf. McDaniel et al., 2004), which could have slowed down the lexical decision even further.

It is interesting to note that the associative mechanism (Moscovitch, 1994) that we have suggested as one mechanism for supporting spontaneous retrieval is a general one that could be activated in either PM or RM contexts. As Moscovitch (1994) has proposed, all that is needed for reflexive retrieval is that a good association is formed between the two cues or a cue and an action and that the cue is fully processed at retrieval. Thus the finding of slowing for both RM and PM items is entirely in line with this view.

Although these results demonstrate that cognitive processes were spontaneously engaged when target events were encountered, our measure of slowing is unlikely to be a precise measure of the cognitive processes. This is because the noticing and/or associative retrieval processes are surely probabilistic in nature and do not always succeed when a target is presented. Thus, our estimate of slowing probably represents an average over trials in which spontaneous retrieval did and did not occur.

On the surface, our finding of slowed responding to PM targets conflicts with findings of faster responding to intention-related materials (known as the intention superiority effect; Goschke \& Kuhl, 1993; Marsh, Hicks, \& Bink, 1998). In the Marsh et al. article, for example, participants read word scripts with each containing five action phrases. Later, lexical decisions for items from scripts that were to be performed were made more quickly than those from to be ignored scripts. Without further research, it is difficult to know which factor or factors are responsible for slowing in our research and faster responding in theirs. Important factors, however, may be that participants in intention-superiority experiments were exposed to many target (script) items, and these were the intended response activities, not cues for performing the script (i.e., participants were told that they would be cued by the experimenter using the title of the script). Also, the context for performing the actions (not on the computer) was very different from that of the lexical decision task. By contrast, in our study, participants only had one target event on each trial, and each was associated with a specific response in the context of the computer task.

\section{General Discussion}

To summarize, the results showed that whether performing a PM task produces costs to the ongoing task depends on a variety of factors. Specifically, the presence of costs depended on whether the ongoing task encouraged focal processing of the target, the instructional emphasis on the PM task, the number of target events, the duration of the ongoing task, and individual differences. Although past research has provided evidence that monitoring is involved in PM (Marsh et al., 2003; Smith, 2003), the present research is important in showing that spontaneous retrieval processes alone can produce prospective remembering. There were conditions in Experiments 1-3 in which there were no significant costs to the ongoing task of performing a PM task, and yet PM performance was high. Also, in Experiment 4, with a focal target event, those participants who showed no evidence of monitoring had high-PM performance and performed at a level equivalent to those who showed evidence of monitoring. Moreover, Experiment 5 demonstrated the existence of spontaneous retrieval processes under conditions in which the PM demands were suspended. These results are difficult to interpret within the view that monitoring is always necessary for PM retrieval (Smith, 2003; Smith \& Bayen, 2004). Instead, the results support our view that people rely on multiple processes in PM situations.

Our view that people do not rely exclusively on a monitoring process is based on two important assumptions of the most developed and current monitoring view (Smith, 2003; see also Smith \& Bayen, 2004). One is that monitoring is a capacity consuming 
process that interferes with the speed of performing the ongoing task. The other is that monitoring is a requirement for PM retrieval. It may be possible, however, to develop alternative assumptions regarding the monitoring process, and these might accommodate many of the present results. One might argue that monitoring for a single focal target event is a relatively simple process that can be accomplished without detectable costs. This interpretation seems unlikely because high-emphasis instructions, which were assumed to stimulate monitoring, did significantly increase costs on the ongoing tasks in the focal target condition. If the monitoring process were essentially resource free with a single focal target, costs should not have occurred in any of the single focal-target conditions.

Another possible explanation for the failure to find significant costs in the moderate-emphasis focal condition is that participants may have monitored only occasionally, perhaps periodically "sneaking" in some monitoring (cf. Reitman, 1974), and thus the costs were not detectable. But, it is important to realize that Smith's (2003) theory is clear in maintaining that monitoring is necessary for retrieval, and, thus, lower levels of monitoring should have resulted in lower PM performance. The present paradigm was sensitive to that possibility. In Experiment 1, instructional emphasis on the PM task was used to affect levels of monitoring. In the nonfocal condition, moderate-emphasis instructions lowered monitoring, as indexed by costs, relative to high emphasis, and the attenuated monitoring was associated with significant reductions in PM relative to the high-emphasis condition. In Experiment 2, when monitoring declined across trials-again as signaled by decreasing costs - there was a concomitant decrease in PM levels. Thus, if an absence of costs in the moderate-emphasis focal condition indeed reflected a relatively low level of a monitoring process that was necessary for PM, then PM performance should have been similarly low in this condition. Given that this did not occur, the results support the view that there is another, relatively cost-free process (i.e., spontaneous retrieval; e.g., see Ste-Marie \& Jacoby, 1993) that is involved in PM retrieval. Therefore, the results are very much in line with the multiprocess theory (McDaniel \& Einstein, 2000) that assumes that a variety of cognitive processes can be recruited to support PM retrieval.

Although spontaneous retrieval processes can mediate PM retrieval, it is also clear that monitoring can improve PM and especially so under conditions in which spontaneous retrieval is less likely (e.g., Experiment 1; see also Kliegel et al., 2004). It appears that participants have good metacognitive awareness of the situations that warrant monitoring (i.e., nonfocal targets, multiple targets). On the basis of the individual differences results in Experiment 4 as well as the general finding of nonzero (albeit nonsignificant) costs with a single focal target in Experiments 1-3, it also appears that at least some of the participants monitor at least some of the time even under conditions that encourage spontaneous retrieval. It is interesting to note, however, that at least with the single focal targets used in this research, there was no evidence that monitoring was necessary for producing high levels of prospective remembering.

Following the important work of Marsh et al. (2003; Marsh, Hicks, \& Cook, 2005) and Smith (2003), the main strategy of the present research was to examine costs on the ongoing task as an index of monitoring. However, there are limitations to this approach for specifying the underlying processes. Costs may instead reflect occasional rehearsal of the target event, reflections concerning the number and location of PM targets or possibly missing a target, as well as other possibilities (cf., Guynn, 2003; Marsh et al., 2005). With these caveats in mind, however, it seems likely that people monitor under some PM conditions, and further research is needed to specify the nature of these monitoring processes. For instance, a reviewer noted that perhaps the focal condition was so easy that it required very little monitoring. For this kind of interpretation to be fruitful, one needs (a) to specify how within a monitoring framework, low levels of monitoring can be sufficient to produce high levels of PM performance and (b) to provide a theoretically grounded metric of what constitutes an easy PM condition, all things being equal. Within our multiprocess perspective, a difficulty dimension can be related to parameters that influence whether monitoring is necessary (e.g., nonfocal, focal), such that "easier" PM tasks would be those for which spontaneous retrieval is highly probable (McDaniel \& Einstein, 2000). Of course, from the multiprocess perspective, further research is also needed to specify the character of spontaneous retrieval processes, but the point is that these processes must be included in a comprehensive account (in the absence of a monitoring theory that addresses the above issues).

The finding that people recruit different processes for different kinds of PM situations is useful for understanding existing patterns in the literature, for example patterns showing that divided attention and aging sometimes affect PM and sometimes do not (see McDaniel \& Einstein, 2000, for detailed discussion). In order to better understand monitoring and spontaneous retrieval processes and how they are affected by different variables (e.g., delay, divided attention, age of participants), researchers may want to design their studies to encourage one process or the other. Researchers should also consider the roles of these processes when considering real-world applications. For example, following from our view that spontaneous retrieval is the more likely process in long-term real-world PM, when interested in generalizing to these situations, researchers may want to discourage monitoring processes.

Our results showing that spontaneous retrieval processes can drive prospective remembering are highly consistent with those of Gollwitzer and colleagues (Brandstätter, Lengfelder, \& Gollwitzer, 2001; Gollwitzer, 1999) showing that this kind of process can be used to improve memory for intended actions. They have shown that implementation intentions are highly effective in remembering or complying with intentions such as keeping deadlines (Gollwitzer \& Brandstätter, 1997) and performing breast self-examinations (Orbell, Hodgkins, \& Sheeran, 1997). Implementation intentions specifically link intended actions to eliciting cues and take the form of "When situation $x$ arises, I will perform $y$ " (Gollwitzer, 1999, p. 494). Their interpretation of the demonstrated benefits of this strategy is that implementation intentions allow people to switch from "conscious and effortful control" of their intentions (similar to a monitoring view) to being "automatically controlled" by the presence of the target events that cue the intended actions (Gollwitzer, 1999, p. 494). In line with these assumptions, Chasteen, Park, and Schwartz (2001) and Liu and Park (2004) found that older adults, who are thought to have reduced working memory resources (Salthouse, 1991), significantly improved their PM with the use of implementation intentions. 
Our assumption that there is a bias to accomplish PM retrieval with spontaneous retrieval processes emanates from both empirical and logical concerns. As demonstrated in this research as well as that of Marsh et al. (2003), when participants were given a single focal target event, there was little evidence of monitoring. From a rational perspective, when the delays between forming the intention and the opportunity to respond are substantial, it would seem adaptive to have a system that allows spontaneous retrieval so as not to compromise performance of ongoing activities. This analysis is consistent with that of Bargh and Chartrand (1999) who have argued that most of our behaviors are not initiated by conscious will over a broad range of situations but rather are automatically triggered in response to the presence of environmental stimuli. In addition, they have proposed that we have a limited capacity for conscious control over behavior and that this "limited resource is quickly used up" (p. 476). Research along these lines has shown that participants who expend conscious effort in one domain have subsequent difficulty sustaining conscious effort in another domain (Baumeister, Bratslavsky, Muraven, \& Tice, 1998; Muraven, Tice, \& Baumeister, 1998). The results of Experiment 2 suggest that monitoring for a PM target is a controlled process that is difficult to maintain over extended periods. From this perspective, it seems unlikely that most people normally rely on constant and capacity-consuming processes when faced with PM demands over anything other than brief delays.

\section{References}

Banaji, M. R., \& Hardin, C. D. (1996). Automatic stereotyping. Psychological Science, 7, 136-141.

Bargh, J. A. (1994). The four horsemen of automaticity: Awareness, efficiency, intention, and control in social cognition. In R. S. Wyer, Jr., \& T. K. Srull (Eds.), Handbook of social cognition (2nd ed., pp. 1-40). Hillsdale, NJ: Erlbaum.

Bargh, J. A., \& Chartrand, T. L. (1999). The unbearable automaticity of being. American Psychologist, 54, 462-479.

Battig, W. F., \& Montague, W. E. (1969). Category norms of verbal items in 56 categories: A replication and extension of the Connecticut category norms. Journal of Experimental Psychology, 80, 1-46.

Baumeister, R. F., Bratslavsky, E., Muraven, M., \& Tice, D. M. (1998). Ego depletion: Is the active self a limited resource? Journal of Personality and Social Psychology, 74, 1252-1265.

Brandstätter, V., Lengfelder, A., \& Gollwitzer, P. M. (2001). Implementation intentions and efficient action initiation. Journal of Personality and Social Psychology, 81, 946-960.

Chasteen, A. L., Park, D. C., \& Schwartz, N. (2001). Implementation intentions and facilitation of prospective memory. Psychological Science, 12, 457-461.

Craik, F. I. M. (1986). A functional account of age differences in memory. In F. Klix \& H. Hangendorf (Eds.), Human memory and cognitive capabilities: Mechanisms and performances (pp. 409-422). Amsterdam: Elsevier.

Einstein, G. O., \& McDaniel, M. A. (1990). Normal aging and prospective memory. Journal of Experimental Psychology: Learning, Memory, and Cognition, 16, 717-726.

Einstein, G. O., \& McDaniel, M. A. (1996). Retrieval processes in prospective memory: Theoretical approaches and some new empirical findings. In M. Brandimonte, G. O. Einstein, \& M. A. McDaniel (Eds.), Prospective memory: Theory and applications (pp. 115-142). Mahwah, NJ: Erlbaum.

Einstein, G. O., McDaniel, M. A., Williford, C. L., Pagan, J. L., \&
Dismukes, R. K. (2003) Forgetting of intentions in demanding situations is rapid. Journal of Experimental Psychology: Applied, 9, 147-162.

Einstein, G. O., Smith, R. E., McDaniel, M. A., \& Shaw, P. (1997). Aging and prospective memory: The influence of increased task demands at encoding and retrieval. Psychology and Aging, 12, 479-488.

Ellis, J. (1996). Prospective memory or the realization of delayed intentions: A conceptual framework for research. In M. Brandimonte, G. O. Einstein, \& M. A. McDaniel (Eds.), Prospective memory: Theory and applications (pp. 1-22). Mahwah, NJ: Erlbaum.

Gollwitzer, P. M. (1999). How can good intentions become effective behavior change strategies? American Psychologist, 54, 493-503.

Gollwitzer, P. M., \& Brandstätter, V. (1997). Implementation intentions and effective goal pursuit. Journal of Personality and Social Psychology, 73, 186-199.

Goschke, T., \& Kuhl, J. (1993). Representation of intentions: Persisting activation in memory. Journal of Experimental Psychology: Learning, Memory, and Cognition, 19, 1211-1226.

Guynn, M. J. (2003). A two-process model of strategic monitoring in event-based prospective memory: Activation/retrieval mode and checking. International Journal of Psychology, 38, 245-256.

Guynn, M. J., McDaniel, M. A., \& Einstein, G. O. (2001). Remembering to perform actions: A different type of memory? In H. D. Zimmer, R. L. Cohen, M. J. Guynn, J. Engelkamp, R. Kormi-Nouri, \& M. A. Foley (Eds.), Memory for action: A distinct form of episodic memory? (pp. 25-48). New York: Oxford University Press.

Johnson, M. K., \& Sherman, S. J. (1990). Constructing and reconstructing the past and the future in the present. In E. T. Higgins \& R. M. Sorrentino (Eds.), Handbook of motivation and cognition: Foundations of social behavior, Vol. 2 (pp. 482-526). New York: Guilford Press.

Kliegel, M., Martin, M., McDaniel, M. A., \& Einstein, G. O. (2004). Importance effects on performance in event-based prospective memory tasks. Memory, 12, 553-561.

Kvavilashvili, L. (1987). Remembering intention as a distinct form of memory. British Journal of Psychology, 78, 507-518.

Kvavilashvili, L., \& Ellis, J. (1996). Varieties of intentions: Some distinctions and classifications. In M. Brandimonte, G. O. Einstein, \& M. A. McDaniel (Eds.), Prospective memory: Theory and applications (pp. 23-52). Mahwah, NJ: Erlbaum.

Liu, L. L., \& Park, D. C. (2004). Aging and medical adherence: The use of automatic processes to achieve effortful things. Psychology and Aging, 19, 318-325.

Marsh, R. L., \& Hicks, J. L. (1998). Event-based prospective memory and executive control of working memory. Journal of Experimental Psychology: Learning, Memory, and Cognition, 24, 336-349.

Marsh, R. L., Hicks, J. L., \& Bink, M. L. (1998). Activation of completed, uncompleted, and partially completed intentions. Journal of Experimental Psychology: Learning, Memory, and Cognition, 24, 350-361.

Marsh, R. L., Hicks, J. L., \& Cook, G. I. (2005). On the relationship between effort toward an ongoing task and cue detection in event-based prospective memory. Journal of Experimental Psychology: Learning, Memory, and Cognition, 31, 68-75.

Marsh, R. L., Hicks, J. L., Cook, G. I., Hansen, J. S., \& Pallos, A. L. (2003). Interference to ongoing activities covaries with the characteristics of an event-based intention. Journal of Experimental Psychology: Learning, Memory, and Cognition, 298, 861-870.

Marsh, R. L., Hicks, J. L., \& Watson, V. (2002). The dynamics of intention retrieval and coordination of action in event-based prospective memory. Journal of Experimental Psychology: Learning, Memory, and Cognition, 28, 652-660.

Maylor, E. A. (1996). Age-related impairment in an event-based prospective memory task. Psychology and Aging, 11, 74-78.

Maylor, E. A., Darby, R. J., Logie, R. H., Della Sala, S., \& Smith, G. (2002). Prospective memory across the lifespan. In P. Graf \& N. Ohta 
(Eds.), Lifespan development of human memory (pp. 235-256). Cambridge, MA: The MIT Press.

McDaniel, M. A., \& Einstein, G. O. (2000). Strategic and automatic processes in prospective memory retrieval: A multiprocess framework. Applied Cognitive Psychology, 14, S127-S144.

McDaniel, M. A., Guynn, M. J., Einstein, G. O., \& Breneiser, J. (2004). Cue-focused and reflexive-associative processes in prospective memory retrieval. Journal of Experimental Psychology: Learning, Memory, and Cognition, 30, 605-614.

McDaniel, M. A., Robinson-Riegler, B., \& Einstein, G. O. (1998). Prospective remembering: Perceptually driven or conceptually driven processes? Memory \& Cognition, 26, 121-134.

Moscovitch, M. (1994). Memory and working with memory: Evaluation of a component process model and comparisons with other models. In D. L. Schacter \& E. Tulving (Eds.), Memory systems (pp. 269-310). Cambridge, MA: MIT Press.

Muraven, M., Tice, D. M., \& Baumeister, R. F. (1998). Self-control as a limited resource: Regulatory depletion patterns. Journal of Personality and Social Psychology, 74, 774-789.

Nowinski, J., \& Dismukes, R. K. (in press). Effects of ongoing task context and target typicality on prospective memory performance: The importance of associative cueing. Memory.

Orbell, S., Hodgkins, S., \& Sheeran, P. (1997). Implementation intentions and the theory of planned behavior. Personality and Social Psychology Bulletin, 23, 945-954.

Park, D. C., Hertzog, C., Kidder, D. P., Morrell, R. W., \& Mayhorn, C. B. (1997). Effect of age on event-based and time-based prospective memory. Psychology and Aging, 12, 314-327.

Posner, M. I., \& Snyder, C. R. (1975). Attention and cognitive control. In R. L. Solso (Ed.), Information processing and cognition: The Loyola symposium (pp. 55-85). Hillsdale, NJ: Erlbaum.

Rastle, K., Harrington, J., \& Coltheart, M. (2002). 358,534 nonwords: The ARC nonword database. Quarterly Journal of Experimental Psychology: Human Experimental Psychology, 55(A), 1339-1362.

Ratcliff, R. (1979). Group reaction time distributions and an analysis of distribution statistics. Psychological Bulletin, 86, 446-461.
Raven, J. C. (1965). Mill Hill Vocabulary Scale. London: H. K. Lewis.

Reese, C. M., \& Cherry, K. E. (2002). The effects of age, ability, and memory monitoring on prospective memory task performance. Aging, Neuropsychology, and Cognition, 9, 98-113.

Reitman, J. S. (1974). Without surreptitious rehearsal, information in short-term memory decays. Journal of Verbal Learning and Verbal Behavior, 13, 365-377.

Rendell, P. G., McDaniel, M. A., Forbes, R. D., \& Einstein, G. O. (2005). Age-related effects in prospective memory are modulated by ongoing task complexity and relation to target cue. Manuscript submitted for publication.

Salthouse, T. A. (1991). Theoretical perspectives on cognitive aging. Hillsdale, NJ: Erlbaum.

Shallice, T., \& Burgess, P. (1991). Deficits in strategy application following frontal lobe damage in man. Brain, 114, 727-741.

Smith, R. E. (2003). The cost of remembering to remember in event-based prospective memory: Investigating the capacity demands of delayed intention performance. Journal of Experimental Psychology: Learning, Memory, and Cognition, 29, 347-361.

Smith, R. E., \& Bayen, U. J. (2004). A multinomial model of event-based prospective memory. Journal of Experimental Psychology: Learning, Memory, and Cognition, 30, 756-777.

Ste-Marie, D. M., \& Jacoby, L. L. (1993). Spontaneous versus directed recognition: The relativity of automaticity. Journal of Experimental Psychology: Learning, Memory, and Cognition, 19, 777-788.

Toglia, M. P., \& Battig, W. F. (1978). Handbook of semantic word norms. Hillsdale, NJ: Erlbaum.

Tulving, E. (1983). Elements of episodic memory. New York: Oxford University Press.

Tulving, E. (2004, May). Memory, consciousness, and time. Keynote address presented at the 16th Annual Convention of the American Psychological Society, Chicago, IL.

Received August 17, 2004 Revision received May 10, 2005 Accepted May 12, 2005

\section{E-Mail Notification of Your Latest Issue Online!}

Would you like to know when the next issue of your favorite APA journal will be available online? This service is now available to you. Sign up at http://watson.apa.org/ notify/ and you will be notified by e-mail when issues of interest to you become available! 